\title{
$\nabla$ Effect of Mindful Outdoor Walking on Attention Among Independent Rural Elderly
}

\section{IJCRR}

Section: Healthcare

Sci. Journal Impact

Factor: 6.1 (2018)

ICV: 90.90 (2018)

(c) (7) (8)

Copyright@IJCRR

\section{S. Anandh ${ }^{1}$, G. Varadharajulu ${ }^{2}$, Mahendra M. Alate ${ }^{3}$, Dhiraj Mane Patil ${ }^{4}$}

\author{
'Professor\& HOD, Physiotherapy in Community Health Sciences, Krishna College of Physiotherapy, KIMSDU, Karad, Maharashtra 415110, \\ India; ${ }^{2}$ Dean, Faculty of Physiotherapy, Krishna lnstitute of Medical Sciences Deemed To Be University, Karad, Maharashtra 415110, India; \\ 3.4Statistician, Director of Research Office, Krishna Institute of Medical Sciences Deemed To Be University, Karad, Maharashtra 415110, India.
}

\section{ABSTRACT}

Introduction: Mindful walking in other words called "conscious walking " technique which has been observed from Afghan nomads who travelled kilometres on foot quickly and effectively. This Afghan walking is a special kind of trekking called "holistic march", the art of walking with one's conscience. It includes a form of yoga that consciously absorbs energy from the air, synchronizing the steps with breathing pattern.

Objective: The study aims to find the influence of mindful outdoor walking on attention on independent rural elderly.

Methods: 192 subjects randomly selected into two groups (undergoing Normal \& Mindful walking) were included for the study. Inclusion criteria: All independent elderly above 65yearsof both genders / Independent despite clinical diagnosis as Diabetes Mellitus, Hypertension, etc. / Post-surgical conditions like PTCS and CABG / medically stable cases excluding Medically unstable cases / Chronic illness \& Life-threatening medical issue / Uncooperative, Psychiatric elderly patients / Amputation, Poliomyelitis / Hearing and vision deficit.

Results: State Mindfulness Scale for Physical activity (SMS - PA). The intervention is of 8 weeks period with regular 30 minutes of walking sessions in the morning for 6 times per week including a10 minutes warm-up sessions / and cool down the procedure for 10 minutes. Using relevant statistical measures the outcome measure had been analyzed. It was observed that the elderly had improved significantly on both state mindfulness of the mind and body of Group B who had undergone Mindful walking. It is so important for physiotherapists to be aware of these strategies and incorporate them into the management of fall prevention among the elderly.

Conclusion: The study concludes that it will have beneficial effects on the elderly individual's instrumental activities of daily living. The study aims at formulating a self-reliant approach to the elderly and train themselves to their threshold levels of exercise capacity.

Key Words: Elderly, Mindfulness, Meditation, Attention, Outdoor walking, Geriatric Walking Program

\section{INTRODUCTION}

An ageing population is a universal phenomenon experienced by all countries in the world. The global geriatric population $>60$ years age group was 962 million in the year 2017 and is said to be doubled by year $2050 .{ }^{1}$ Frailty in the simplest definition is increasing vulnerability to adverse health outcomes. Several studies have already been undertaken on age-related cognitive decline in the elderly. Meditation has shown highly positive results from/of mental and physical aspects of meditators. ${ }^{2}$ Socio-demographic factors \& Health status are the two categories influencing frailty. The appropriate Physical activity which, is mandatory without risk of specific utilizing efficient body mechanics, is walking. The safest mobility component is walking, which is conferred to great benefit as a modifiable factor of frailty prevention. More literature supports the favourable effects of mindfulness meditation while walking and other simple tasks on the cognitive function of the elderly. ${ }^{3,4}$ Quality attentiveness from physiotherapists towards framing the best possible physical activity is essential concerning the elderly population.

Mindful walking, in other words, called "conscious walking" technique that has been observed from Afghan nomads who travelled kilometers on foot quickly and effectively. It is a special kind of trekking called "holistic march", the art of walking with one's conscience. It's a form of yoga that consciously absorbs energy from the air, synchronizing the

Corresponding Author:

Dr. S. Anandh, Professor \& HOD, Physiotherapy in Community Health Sciences, Krishna College of Physiotherapy, KIMSDU, Karad, Maharashtra 415110, India.

ISSN: 2231-2196 (Print) ISSN: 0975-5241 (Online)

Received: $29.07 .2020 \quad$ Revised: 06.10 .2020

Accepted: 21.11 .2020

Published: 05.01 .2021 
steps with breathing pattern..$^{5-8}$ The first study in 2010 , conducted by Li et al. ${ }^{6}$ Investigate that the psychological effects of a green environment would also have an impact on physiological outcomes. The authors concluded that walking in forest environments significantly increased human immune function among the participants of the study. In the followup study, the authors concluded that walking in a forest area compared to walking in an urban environment significantly reduced blood pressure. In the present study we aimed to study the influence of mindful outdoor walking on attention and Gait speed among independent rural elderly,to study the influence of normal outdoor walking on attention and gait speed among independent rural elderly and compare the influence of mindful walking versus normal outdoor walking on attention \& gait speed among independent rural elderly.

\section{MATERIALS AND METHODS}

The study design is a Clinical demonstration project, in other words, Quality improvement project which is an Interventional study completed in a year conducted with a sample size of 192 elderly subjects using a random sampling method. Randomization with a 1:1 ratio was assigned to the elderly veterans' groups. The random assignment set was developed with SAS 9.2 application. The participants were collectively allotted, by an unbiased research nurse, after the signature of the notified permission form as well as completion of the sample evaluation questionnaires to the control and intervention groups.

\section{Statistical Analysis}

The analysis was intended to identify a 2-point differential variance between the intervention as well as the control groups with an intensity of $90 \%$, which involves the dropout rate of roughly $20 \%$, of the main result component of the State Mindfulness scale for Physical activity (SMS - PA).

\section{Outcome Measures}

1. State Mindfulness scale of Physical activity (SMS PA) with two components namely State mindfulness of the mind with a total score - $24 \&$ State mindfulness of the body with a total score -24 .

2. Gait speed: 4-meter gait speed test.

\section{Intervention Procedure}

To promote an active lifestyle in older Veterans at rural Maharashtra, we developed an outpatient mindfulness intervention to promote physical activity in older Veterans. This intervention was modelled as a Geriatric Walking Program (GWP). The program was also comprehended at maintaining a specific focus to improve components of frailty and to engage older Veterans in a long-term program of regular physical activity primarily in the easiest form of walking.
We used proven strategies, such as motivational counselling, follow-up phone calls from a physiotherapist, and self-monitoring. Here we report short-term results of this program from the 8 - week follow-up with regular 20 minutes of the walking session in the morning outdoors on muddy track of 6 times per week including a 10-minute warm-up session and cool down the procedure for 10 minutes.

Further, the participating mindful walking intervention patients were motivated and instructed to continue the exercise by themselves' post 4-week research program.

\section{Inclusion Criteria}

All functionally independent elderly, above the age of 65 80 years including both genders with normal vitals were included in the study; Retired senior citizens restricted to their residence most of the time; No history of fall for the past 12 months; Ability to walk $20 \mathrm{~m}$ without human assistance; Ability to speak/read/communicate. All elderly participants were screened for additional medical contraindications using Screening for You (EASY) criteria.

\section{Exclusion Criteria}

Medically unstable patients and Patients with Pacemaker; Chronic illness \& Life-threatening medical issues; All types of disabilities including severe musculoskeletal pathology, neurological conditions, vestibular dysfunction that would affect participation; Uncooperative and Psychiatric elderly patients; Participants scored less below 23 on the MMSE; Subjects who are doing part-time work, Farm work or any other regular work are restricted from the study.

\section{RESULTS}

The outcomes of the statistical analysis of the study are given below in tabulated form (Table 1 to Table 7) with their relevant interpretations.

Table 1: Scoring of State mindfulness of the Mind concerning daily experiences using State Mindfulness Scale for Physical Activity (SMS - PA): Pre - Posttest scores of Group - A (Normal Walking).

\begin{tabular}{|c|c|c|c|c|}
\hline \multicolumn{5}{|c|}{ SMS Mind Score Group - A (Normal Walking) } \\
\hline Score & Mean & S.D. & $\begin{array}{c}t \\
\text { Value }\end{array}$ & p-value \\
\hline SMS Mind Score Pre Test & 18.31 & 1.71 & & \\
\hline SMS Mind Score Post Test & 12.01 & 1.46 & & \\
\hline
\end{tabular}

Interpretation: The Post Test scores of State mindfulness of the Mind have reduced which shows that the attention is improved significantly with reduced thoughts. 
Table 2: Scoring of State mindfulness of the Body concerning a day - to - day experiences using State Mindfulness Scale for Physical Activity (SMS - PA): Pre - Post-test scores of Group - A (Normal Walking)

\begin{tabular}{lllll}
\multicolumn{5}{c}{ SMS Body Score Group - A (Normal Walking) } \\
Score & Mean & S.D. & t Value & p-value \\
SMS Body Score Pre Test & 7.31 & 2.55 & & \\
SMS Body Score Post Test & 14.66 & 1.689 & 23.347 & $<$ o.oool S \\
\hline
\end{tabular}

Interpretation: The Post Test scores of State mindfulness of the Body have increased which shows that the attention is improved significantly towards physical activity.

Table 3: Scoring of Gait speed using 4-metre walk duration (Normal Walking): Pre - Post-test scores of Group - A (Normal Walking)

\begin{tabular}{lcccc}
\multicolumn{4}{l}{ 4-metre walk duration } & Group - A (Normal Walking) \\
Score & Mean & S.D. & t value & p-value \\
$\begin{array}{l}\text { 4-metre walk duration } \\
\text { Pre Test }\end{array}$ & 5.11 & 0.3884 & & \\
$\begin{array}{l}\text { 4-metre walk duration } \\
\text { Post Test }\end{array}$ & 4.636 & 0.4305 & 8.079 & < o.ooor \\
\hline
\end{tabular}

Interpretation: The Post Test scores of Gait speed is significant which is evident with reduced duration of the test results.

Table 4: Scoring of State mindfulness of the Mind with regard to day - to - day experiences using State Mindfulness Scale for Physical Activity (SMS - PA): Pre - Post test scores of Group - B (Mindful Walking)

\begin{tabular}{lcccc}
\multicolumn{5}{c}{ SMS Mind Score Group - B (Mindful Walking) } \\
Score & Mean & S.D. & $\begin{array}{c}\text { t } \\
\text { value }\end{array}$ & p-value \\
SMS Mind Score Pre Test & 18.031 & 1.809 & 37.348 & $<0.0001$ S \\
SMS Mind Score Post Test & 7.80 & 1.932 & & \\
\hline
\end{tabular}

Interpretation: The Post Test scores of State mindfulness of the Mind have reduced which shows that the attention is improved significantly with reduced thoughts in the experimental group of Mindful walking.
Table 5: Scoring of State mindfulness of the Body concerning a day - to - day experiences using State Mindfulness Scale for Physical Activity (SMS - PA): Pre - Post-test scores of Group - B (Mindful Walking)

\begin{tabular}{lcccc}
\multicolumn{5}{c}{ SMS Body Score Group - B (Mindful Walking) } \\
Score & Mean & S.D. & t value & p value \\
SMS Body Score Pre Test & 6.26 & 1.51 & & \\
SMS Body Score Post Test & 19.33 & 0.95 & 71.390 & $<0.0001$ S \\
\hline
\end{tabular}

Interpretation: The Post Test scores of State mindfulness of the Body have increased which shows that the attention is improved significantly towards physical activity in the experimental group of Mindful walking.

Table 6: Scoring of Gait speed using 4-metre walk duration (Normal Walking): Pre - Post-test scores of Group - B (Mindful Walking)

\begin{tabular}{lcccc}
$\begin{array}{l}\text { 4-metre walk duration } \\
\text { Score }\end{array}$ & Mean - B (Mindful Walking) \\
4-metre walk duration & 4.96 & 4.14 & & \\
$\begin{array}{l}\text { Pre Test } \\
\text { 4-metre walk duration }\end{array}$ & 0.2582 & 0.4202 & 16.260 & $<0.0001$ S \\
Post Test & & & & \\
\hline
\end{tabular}

Interpretation: The Post Test scores of Gait speed is significant which is evident with reduced duration of the test results in the experimental group of Mindful walking.

Table 7: The comparative Post-test scores of Conventional Group A (Normal Walking) \& Experimental Group B (Mindful Walking)

\begin{tabular}{|c|c|c|c|}
\hline COMPARISON OF I & $\begin{array}{l}\text { JORMAL WALI } \\
\text { WALKING }\end{array}$ & ING \& & INDFUL \\
\hline $\begin{array}{l}\text { POST TEST COMPAR- } \\
\text { ISON SCORES }\end{array}$ & Mean \pm S D & t value & p-value \\
\hline $\begin{array}{l}\text { SMS Mind Score Post } \\
\text { Test Group - A (Normal } \\
\text { Walking) } \\
\& \\
\text { SMS Mind Score Post } \\
\text { Test Group - B (Mind- } \\
\text { ful Walking) }\end{array}$ & $\begin{array}{l}12.01 \pm 1.4 \\
7.8 \pm 1.982\end{array}$ & 16.74 & $<0.0001 \mathrm{~S}$ \\
\hline $\begin{array}{l}\text { SMS Body Score Post } \\
\text { Test Group A (Normal } \\
\text { Walking) } \\
\& \\
\text { SMS Body Score Post } \\
\text { Test Group - B (Mindful } \\
\text { Walking) }\end{array}$ & $\begin{array}{c}14.60 \pm 1.681 \\
19.33 \pm 0.9588\end{array}$ & 23.860 & $<0.0001 \mathrm{~S}$ \\
\hline
\end{tabular}




\section{Table 7: (Continued)}

Gait speed Post Test
Group A Normal Walk-
ing
$\begin{aligned} & \text { \& } \\ & \text { Gait speed Post Test }\end{aligned}$
Group B Mindful Walk-
ing

\section{Comparative results of Group A and Group B}

The comparative Post-test scores of Conventional Group A (Normal Walking) \& Experimental Group B (Mindful Walking) shows high significance concerning Mindful walking. The scores of Group B (experimental group) Mindful walking shows highly significant results with relation to State Mindfulness Scale of Physical Activity with relation to both Mind \& Body component (SMS - PA) and Gait speed i.e., p $<0.0001$

\section{DISCUSSION}

Today mindfulness training has become a widespread approach to ameliorating psychological suffering and maintaining emotional well-being. Besides, the veteran elderly were able to overcome their physical discomforts due to increased attention. The improvement in gait speed is clinically essential, as well as these improvements are supposed to lead to better performance, which would be of therapeutic importance in the long run. The elderly acknowledged better posture and positioning with regular marching, matching steps to their breath. Also, they were able to acknowledge their thoughts and getting more connected to their walking.

The elderly had improved significantly $\mathrm{p}<0.0001$ with both state mindfulness of the mind and body that have undergone Mindful walking. This proves that natural rural area outdoor walking has a positive effect on health overcoming frailty in the elderly. Besides, the study proves that walking itself was found to elicit overall good health despite introducing any variations. The sunlight exposure, muddy track and natural rural environment have a positive influence when the elderly walked in groups focusing attention towards their body motion and breath.

The additional benefits achieved by the elderly are staying motivated, managing pain and breath, increasing walking distances \& speed as well as enhanced psychological benefits as per the elderly groups. The research ensures a provision of continuous and holistic care of the elderly through mindful walking. However, an optimal amount of support is conducive to preserve the functional independence of the elderly. The research further proves that there is also a need for enhancement directed towards mindful walking as per individual needs.

The strength of the study is that we have demonstrated the effect of promoting walking for exercise in a "real world" outdoor setting with regular participation in the elderly. At the same time, the study emphasizes/emphasized that walking speed as one of the frailty characteristics, which may not necessarily to reflect a global change in frailty classification (i.e., non-frail, pre-frail, or frail). The Mindful walking practice assisted them to get better connected with the earth with ease of mobility and nourished mental \& physical health.

The safe execution of low intensity walking program ensures quality body mechanics and continuous dynamic motion with awareness to steps while breathing. The elderly experienced anchoring experience in the present moment and enrich the benefits of the cardiovascular system. This walking school promotes wellness for the elderly in rural communities in a safe progressive challenging manner. In conclusion, this mindful walking program proves as an emotional wellness program too.

Regarding community wellness, most elderly hesitate to ask for help since pride/ego is a barrier. This community welfare projects with elderly mobility as the prime objective have overcome the critical social determinant of health emphasizing elderly mobility daily regularly. The mission of the project is to ensure safe mobility of the elderly in rural communities and it has been found successful as local groups and champions have aroused out of the research project.

\section{CONCLUSION}

Our findings demonstrate that short duration, low-intensity mindful walking intervention improves attention, gait speed and helps in reducing mental stress. This new therapeutic paradigm can be helpful to promote regular physical activity as well as to avoid or improve feebleness in elderly people. The mindful walking program has proved enjoyable overcoming many minor obstacles and assisted the elderly inactive life patterns. Furthermore, it was found that mindfulness in natural surrounding seems to have had a significant influence on one's wellbeing considering physical, psychological, as well as social factors. Besides that, mindful walking in natural rural surroundings is marginally preferable to mindfulness performed in non-natural environments. Fortunately, at this time we have too little knowledge about the effectiveness of various forms of cognitive mindfulness therapy, and therefore, further work is required to understand how an efficient mindfulness intervention can come in the form. Mindful walking in wild nature tends to be more helpful than in non-natural environments, however, the significance of the ecosystem requires more study. 


\section{ACKNOWLEDGEMENTS}

We are grateful for the support to Physiotherapy in Community health sciences and Directorate of Research office, Krishna Institute of Medical Sciences Deemed To Be University, Karad.for the constant guidance and support.

Ethical Issue: Ethical clearance was taken from institutional ethical committee, KIMSDU, Karad.

Funding Sources: Krishna Institute of Medical Sciences Deemed To Be University, Karad.

\section{Conflict of Interest: Nil}

\section{REFERENCES}

1. United Nations, Department of Economic and Social Affairs, Population Division. World Population Aging 2017.

2. Marciniak R, Sheardova K, Cermáková P, Hude`cek D, Šumec $\mathrm{R}$, Hort J. Effect of meditation on cognitive functions in the context of ageing and neurodegenerative diseases. Front Behav Neurosci 2014; 8:17.
3. Kandel ER, Schwartz JH, Jesse, TM, Siegelbaum SA, Hudspeth AJ. In, Kandel, ER (ed). Principles of Neural Sci. $5^{\text {th }}$ edition. McGraw-Hill publishers; 2013;1328-52.

4. LaCaille RA, Masters KS, Heath EM. Effects of cognitive strategy and exercise setting on running performance perceived exertion, affect, and satisfaction. Psychol Sport Excel 2004;5: 461-476.

5. Lakka HM, Laaksonen DE, Lakka TA, Niskanen LK, Kumpusalo E, Tuomilehto J. The metabolic syndrome and total and cardiovascular disease mortality in middle-aged men. J Am Med Asso 2002; 288(21):2709-2716.

6. Li Q, Kobayashi M, Inagaki H, Hirata Y, Hirata K, Li YJ. A day trip to a forest park increases human natural killer activity and the expression of anticancer proteins in male subjects. J Bio Regul Homeost Age 2010;24:157-165.

7. Van den Berg AE, Maas J, Verheij RA,Groenewegen PP. Green space as a buffer between stressful life events and health. Soc Sci Med 2010;70(8), 1203-1210.

8. Rimer J, Dwan K, Lawlor DA, Greig CA, McMurdo, Morley W, Mead GE. Exercise for depression. Cochrane Lib 2012; 3(4): 41-5

9. Brymer S, Davids K, Malabon L. Understanding the psychological health and well-being benefits of physical activity in nature: An ecological dynamics analysis. Ecopsychology 2014;6:189197. 